\title{
ANTENATAL CARE AND PREGNANCY OUTCOME IN GHANA, THE IMPORTANCE OF WOMEN'S EDUCATION
}

Tayie FAK ${ }^{1 *}$ and A Lartey ${ }^{2}$

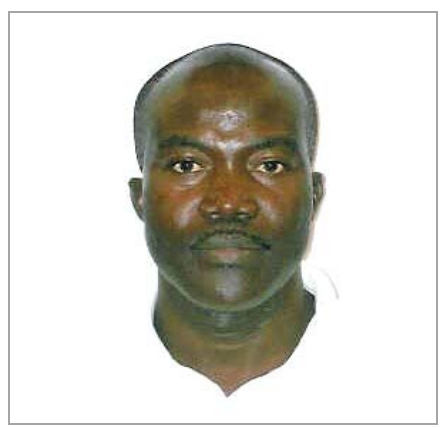

Francis Tayie

Corresponding author email: francis.tayie@gmail.com

${ }^{1}$ Department of Nutrition and Food Science, Auburn University, Alabama, USA

${ }^{2}$ Department of Nutrition and Food Science, University of Ghana, Legon, Ghana. 


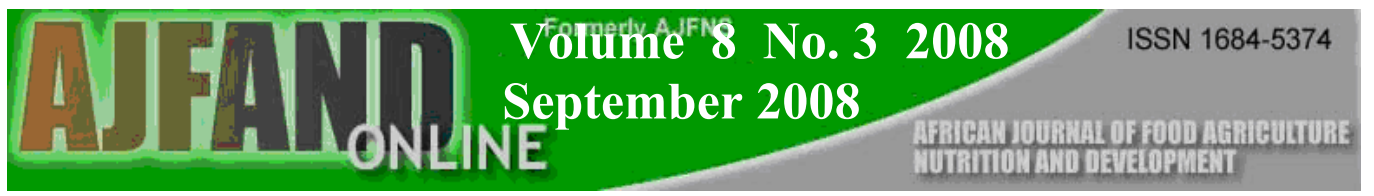

\begin{abstract}
The antenatal characteristics of 503 pregnant women attending maternal and child health clinics in Accra were studied to ascertain the influence of antenatal care on pregnancy outcome. Gestation age of first antenatal care attendance, duration of nutrients supplementation during pregnancy, infant birth-weight and level of education in relation to seeking early antenatal care were studied. A sub-sample comprising 128 were selected for a longitudinal study which assessed monthly haemoglobin concentration of the pregnant women when they reported for antenatal care. Results showed that the level of educational of the pregnant women was important in seeking early antenatal care. Higher educational level associated with early antenatal care attendance. Majority of the subjects attended antenatal care in the $3^{\text {rd }}$ month of pregnancy. The average birth-weight of infants delivered by the 503 pregnant women was $3.02 \pm 0.45 \mathrm{~kg}$ and the prevalence of low birth-weight (birthweight $<2.5 \mathrm{~kg}$ ) was $8.3 \%$. Pregnant women who sought antenatal care before the end of the $3^{\text {rd }}$ month delivered infants whose birth-weights were significantly better compared to those who sought care later $(3.08 \pm 0.44 \mathrm{vs} 2.85 \pm 0.46 \mathrm{~kg}$, respectively, $\mathrm{P}<0.0001)$. Those who received antenatal care before the end of the $3^{\mathrm{rd}}$ month had on average 3.2 times $(95 \% \mathrm{CI}: 1.9-5.2, \mathrm{P}<0.0001)$ better chance of giving birth to a normal weight infant. Pregnant women who received antenatal care and were on multivitamin and mineral supplements for more than 5 months had infants who weighed better than those who received care for lesser duration $(3.04 \pm 0.44$ vs $2.88 \pm 0.55 \mathrm{~kg}$, respectively $\mathrm{P}<0.0001)$. The longitudinal haemoglobin study showed an average haemoglobin concentration of $11.5 \pm 0.6 \mathrm{~g} / \mathrm{dL}, \mathrm{n}=128$. The anaemia rate among the pregnant women ranged from $24-38 \%$ depending on gestation age. Early antenatal care was associated with significant improvement in haemoglobin concentration $(\mathrm{r}=+0.35, \mathrm{P}<0.0001, \mathrm{n}=128)$. It was concluded that early antenatal care is crucial to favourable outcome of pregnancy in this population.
\end{abstract}

Key Words: Antenatal care, birth-weight, haemoglobin level.

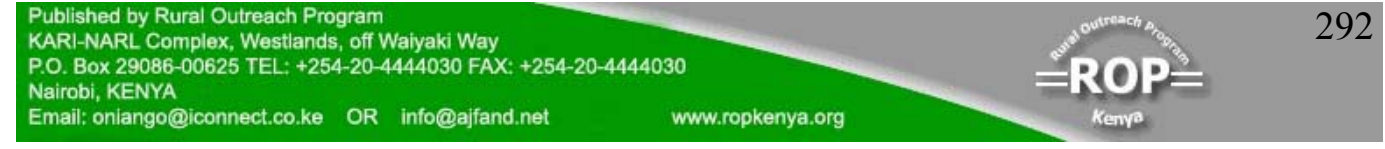




\section{INTRODUCTION}

Among the Millennium Development Goals set in the year 2000 was a three-quarters reduction in maternal and infant mortality rates by the year 2015 [1]. Worldwide, an estimated 515,000 women die of causes related to pregnancy and child birth each year $^{1}$, and their deaths leave one million children motherless [2,3]. Over $99 \%$ of these deaths occur in developing countries [1]. Antenatal care is an important intervention for the wellbeing of the pregnant mother and the expected infant, especially in regions where maternal and infant mortality rates are high. Moreover, there are high prevalence of pregnancy-related deaths and disabilities and infant mortality in subSaharan Africa $[4,5,6]$.

Pregnancy outcome is a measure of the health status of both the infant and mother and it is influenced by several factors including the body weight and height of the mother prior to pregnancy, her nutritional and health status before and during pregnancy [7] and antenatal care and counselling. These, coupled with the associated physiological changes, such as antenatal weight gain and blood volume expansion, interact to determine pregnancy outcome [8]. The physiological changes that occur in pregnancy are necessary for the development of the foetus, regulation of maternal metabolism and preparation for parturition and lactation. Pregnancy may result in discomforts such as antenatal nausea, oedema, gestational goitre, anaemia and gestational diabetes $[7,8]$. The combined effects of these discomforts can lead to unfavourable alteration in food intake and overall nutritional habits. To meet extra nutritional needs and to ensure good health of both infant and mother, multivitamin and mineral supplements (MVMS) are prescribed for pregnant women on their first attendance to maternal and child health $(\mathrm{MCH})$ centres $[9,10,11]$. Pregnant women continue to take daily doses of the supplements and receive regular counselling till parturition.

Pregnant women who seek antenatal care early are likely to be cared for and be on prescribed nutrient supplements for a longer duration than those who delay. The delay in seeking antenatal care may be due to outdated traditional rites and taboos of pregnancy, lack of resources or mere uncertainty [12]. $\mathrm{MCH}$ centres administer MVMS to pregnant women who visit for care. Most of these supplements contain iron, folate and vitamin $\mathrm{B}_{12}$. The biological effects of iron and vitamins supplementation include increased haemoglobin concentration and weight gain. Haemoglobin levels of pregnant women have thus been used as an index of the effectiveness of the MVMS programme [11]. Haemoglobin levels of pregnant women are monitored regularly, mostly monthly, during antenatal visits to prevent antenatal anaemia and to ensure favourable outcome of pregnancy [13]. This study examines the associations between maternal educational level, early antenatal care attendance and pregnancy outcome using birth-weight and maternal haemoglobin concentration as indicators.

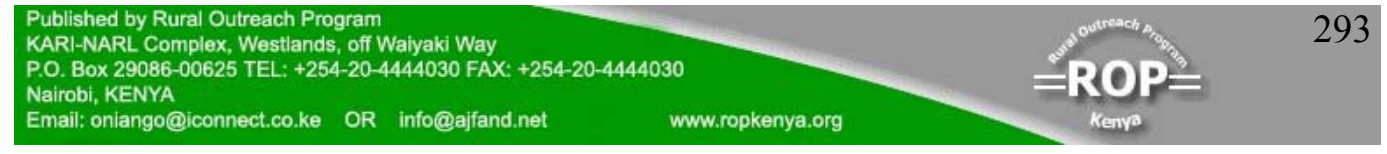




\section{METHODS}

\section{Study population and Sampling}

Four maternal and child health centres served as study sites. They are the University of Ghana Hospital, La Polyclinic, Kaneshie Polyclinic and Nerzit Maternity. The above $\mathrm{MCH}$ centres provide antenatal care and counselling. The location of these $\mathrm{MCH}$ centres portrays participants of variable socio-economic background. Five hundred and three (503) pregnant women were recruited for the study through on-site invitation by word-of-mouth when they reported for antenatal care. The objective of the study was explained to potential participants. All participants completed an informed consent form. Inclusion criteria were absence of chronic disease or complicated pregnancy, age between 20-35 years and willingness to participate. Participants had been immunized against tetanus and were on MVMS in accordance with the protocol for MCH centres controlled by the Ghana Ministry of Health.

\section{Data Collection}

\section{Cross-sectional data}

A study-specific semi-structured questionnaire was used to collect data by person to person interview of the pregnant women. Data collected included socio-economic information, antenatal clinic attendance, gestation age of first antenatal care, educational level and duration of MVMS use. The birth-weights of the infants were recorded from hospital records after delivery. To provide adequate background information on the participants, maternal body weight (measured using an adult weighing scale; Seca M215, Fitness Monitors, UK) and height (using a Holtain stadiometer; Holtain Ltd, Crymmich) were measured in the first trimester.

\section{Haemoglobin data}

A sub-sample of 128 was selected from the 503 pregnant women for a longitudinal study through a systematic random sampling technique [14] after meeting the following selection criteria: confirmation of the pregnancy by the 8th week of gestation, age between 20-35 years, has acceptable haemoglobin concentration (Haemoglobin $\geq 10 \mathrm{~g} / \mathrm{dL}$ ) and absence of chronic disease and uncomplicated pregnancy. The longitudinal study assessed monthly haemoglobin concentrations of the pregnant women when they attended the $\mathrm{MCH}$ centres for antenatal care. The laboratory method used in all four $\mathrm{MCH}$ centres for determination of haemoglobin concentration was the cyanmethaemoglobin method [15]. To assess anaemia prevalence, haemoglobin concentrations were compared to a WHO anaemia cut-point of $11.0 \mathrm{~g} / \mathrm{dL}$ for pregnant women [16].

\section{Data analyses and calculations}

Data were analyzed by using Intercool STATA for windows version 8.0 (STATA Corporation, College Station, Texas) and SAS version 9.1 (SAS Institute Inc., Cary). Analysis of variance and multiple comparison tests using Duncan's method were used to study differences between means of categorical data. Pearson's linear correlation analysis was used to ascertain relationships between variables of interest. We used multinomial logistic regression to analyse discontinuous data. Rules of normality and

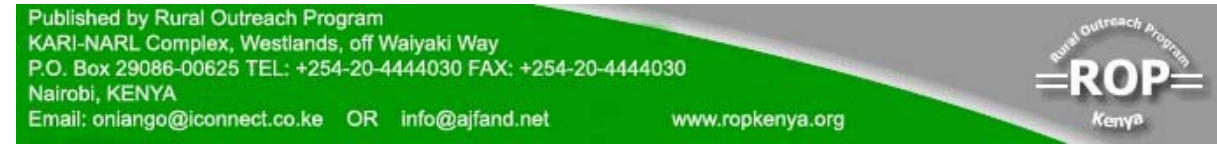


equal variance were satisfied by the observed birth-weight values. Statistical significance differences were tested at $\mathrm{P}<0.05$.

\section{RESULTS}

Table 1 shows some characteristics of the study participants. The average birth-weight of infants delivered by the 503 pregnant women was $3.02 \pm 0.45$ (range: $1.80-4.20$ $\mathrm{kg}$ ). The prevalence of low birth-weight (birth-weight $<2.5 \mathrm{~kg}$ ) [17] was $8.3 \%$ whereas the prevalence of macrosomia (birth-weight $>4.0 \mathrm{~kg}$ ) [17] was $1.6 \%$ among the infants delivered.

Figure 1 shows the antenatal attendance characteristics of the 503 pregnant women in this study. Only about $8 \%$ of the pregnant women had sought antenatal care by the end of the first month during pregnancy. Majority attended the $\mathrm{MCH}$ centres for antenatal care in the $3^{\text {rd }}$ month of pregnancy.

Figure 1 Age of pregnancy at first antenatal care attendance $(n=503)$

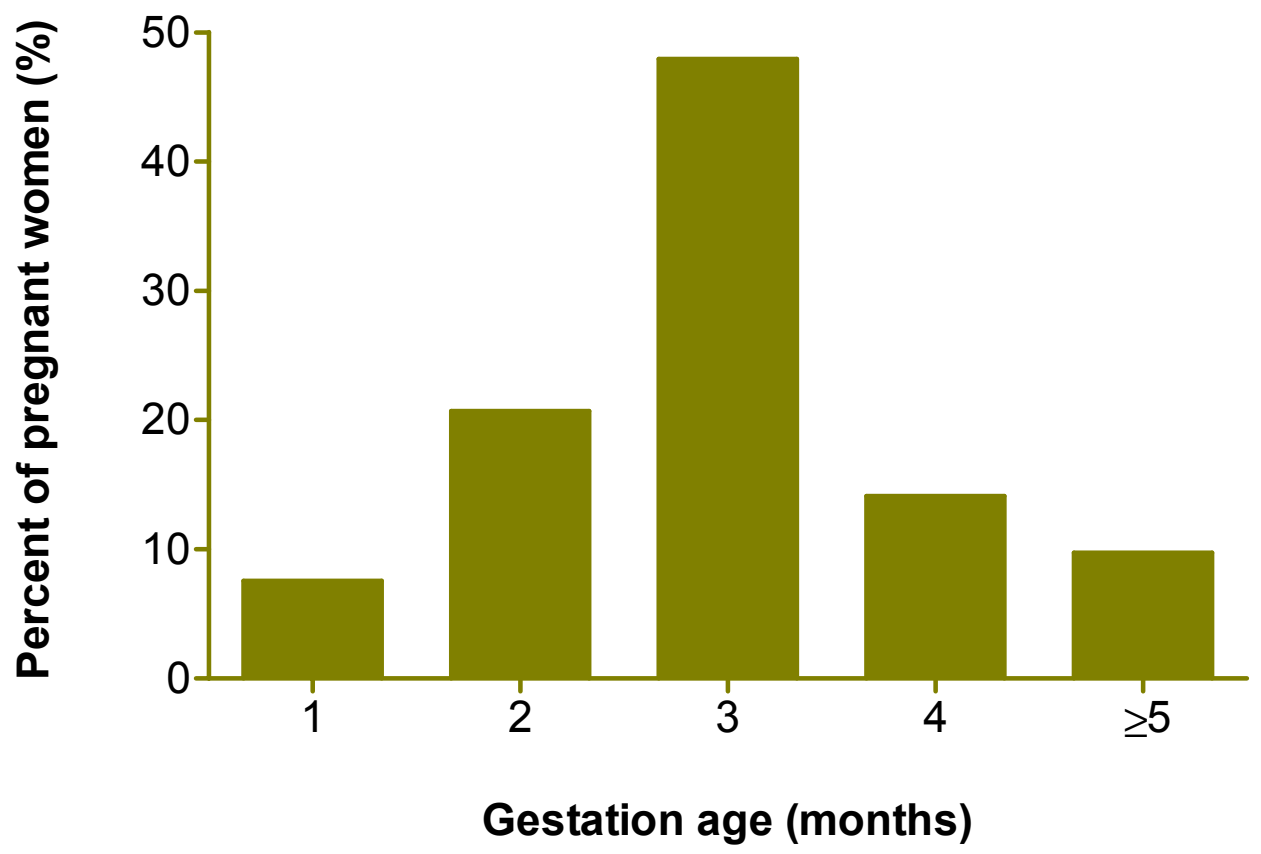

A significantly positive association between maternal educational level and gestational age of first antenatal care attendance $(\mathrm{r}=+0.12, \mathrm{P}<0.01)$ was observed (Figure 2). Mothers who had secondary or tertiary education sought antenatal care earlier, within the $3^{\text {rd }}$ month of pregnancy, earlier than mothers who had middle school education or less. Decreasing educational level related with increasing delay in self-seeking antennal care. Even though educational level associated with early 
antenatal care, there was no significant correlation between maternal educational level and infant birth-weight, $\mathrm{P}>0.05$.

Figure 2 Level of education in relation to early antenatal care attendance $(n=503)$

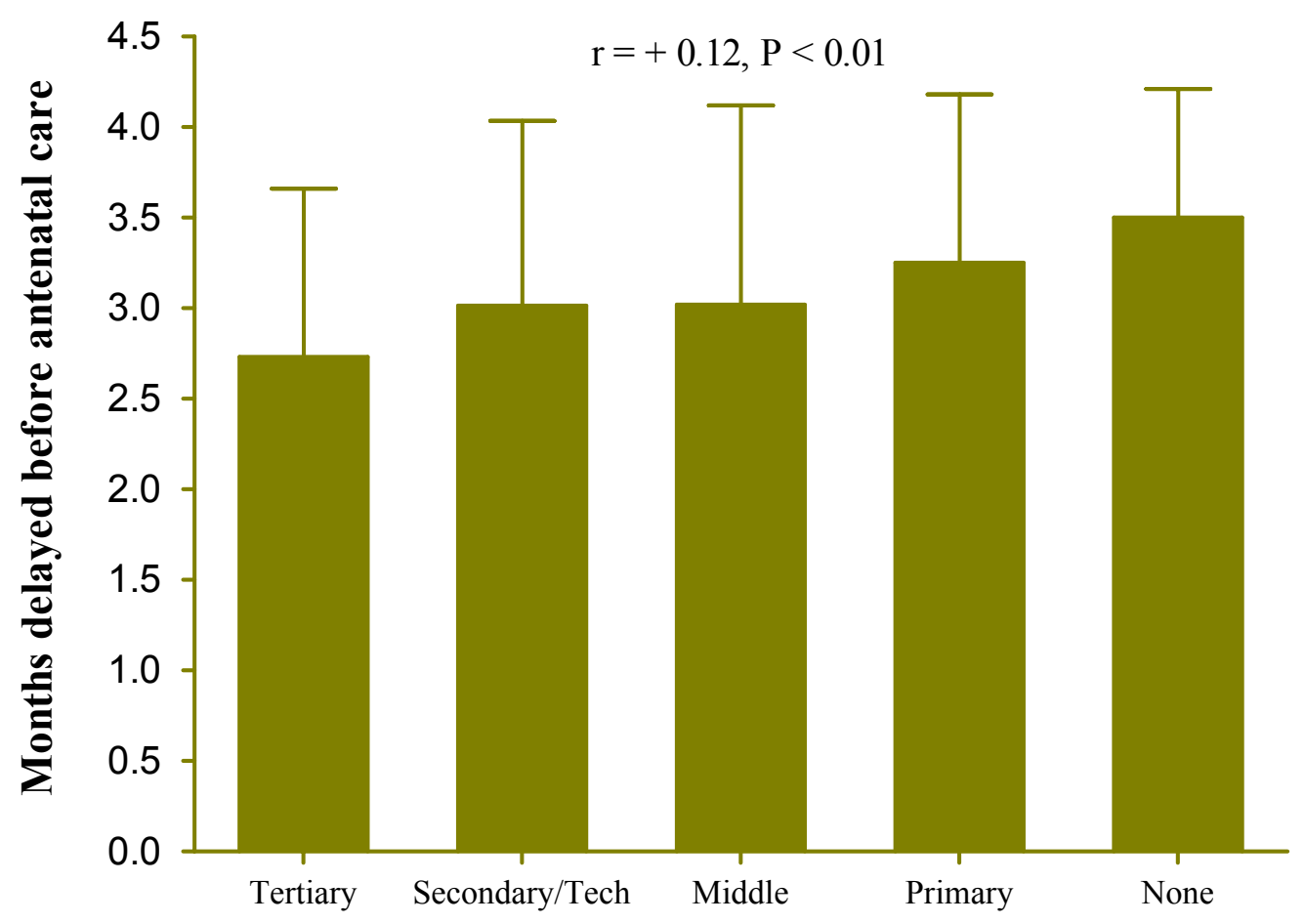

Educational level

Pregnancy outcome, in terms of birth-weight, correlated with the gestational age when pregnant women first sought antenatal care. From Figure 3, the more mothers delayed in seeking antenatal care, the lower was the birth-weight $(\mathrm{r}=-0.16, \mathrm{P}<0.001)$. Mothers who sought antenatal care before the end of the $3^{\text {rd }}$ month had infants who weighed heavier compared to the infants of mothers who sought care later (birthweight; $3.08 \pm 0.44$ vs $2.85 \pm 0.46 \mathrm{~kg}$, respectively, $\mathrm{P}<0.0001)$. Those who sought antenatal care before the end of the $3^{\text {rd }}$ month had on average 3.2 times (95\% CI: $1.9-$ $5.2, \mathrm{P}<0.0001)$ better chance to give birth to a normal weight infant, of birth-weight $\geq 2.5 \mathrm{~kg}[7,8]$. 
Figure 3 Infant birth-weight in relation to gestation age of first antenatal care attendance

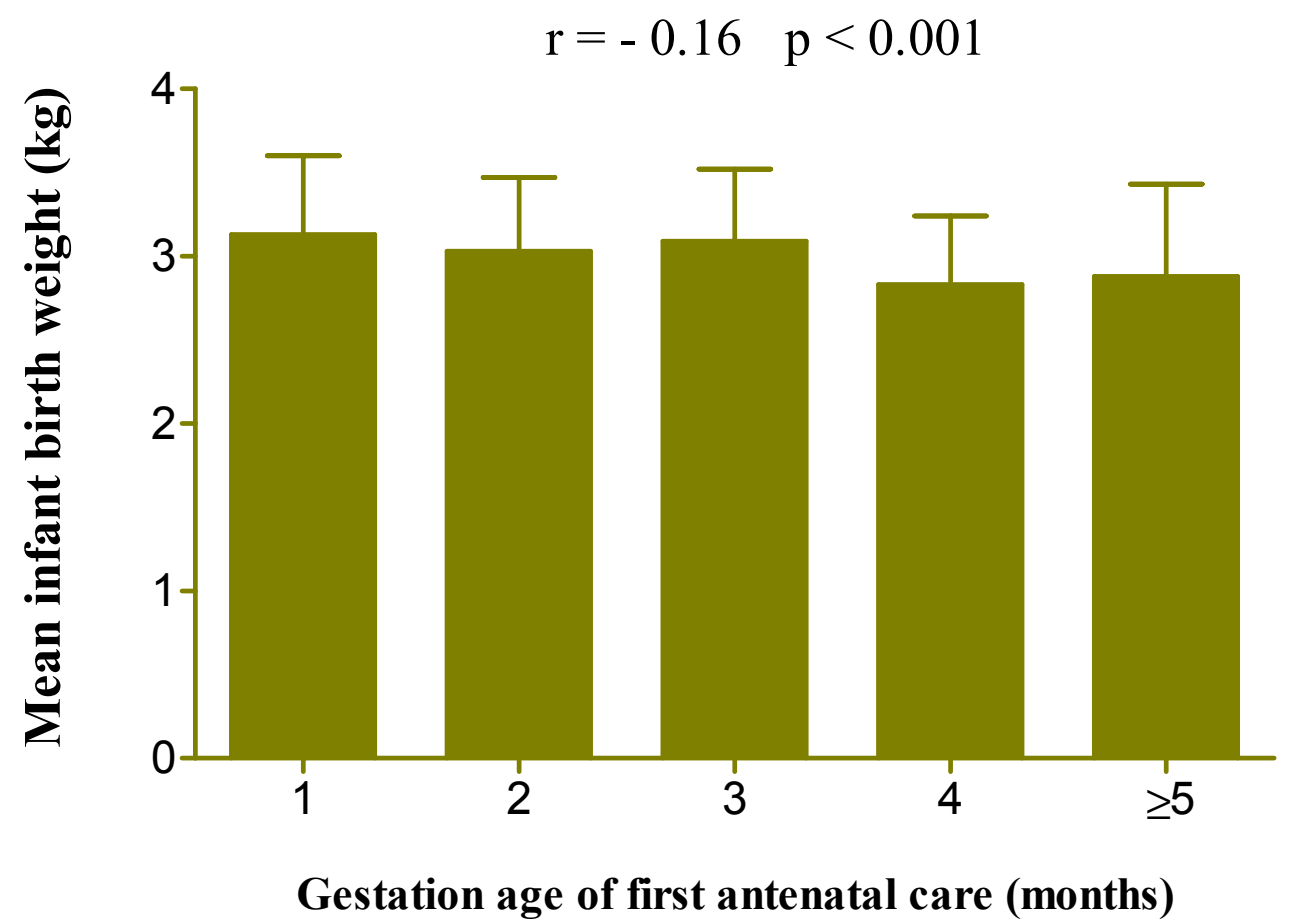

The efficacy of antenatal care and the MVMS during pregnancy was noted by the strongly positive correlation of the duration of care and supplementation with infant birth-weight, $\mathrm{r}=+0.15, \mathrm{P}<0.001, \mathrm{n}=503$ (Table 2). Pregnant women who received antenatal care and were on MVMS for more than 5 months had infants with birthweights significantly higher than those who received care and MVMS for a shorter duration ( $3.04 \pm 0.44$ vs $2.88 \pm 0.55$, respectively, $\mathrm{P}<0.0001, \mathrm{n}=503)$. Mothers who received antenatal care and MVMS for more than 5 months were on average $2.1(95 \%$ CI: $1.1-4.1, \mathrm{P}<0.0001)$ times more likely to give birth to infants whose weights were normal than those who received care and MVMS for a shorter duration.

During pregnancy, the average haemoglobin concentration was $11.5 \pm 0.6 \mathrm{~g} / \mathrm{dL}$ (range: $10.1-13.1 \mathrm{~g} / \mathrm{dL}$ ). The lowest haemoglobin concentrations were observed in the $8^{\text {th }}$ month, mean $11.2 \pm 0.7 \mathrm{~g} / \mathrm{dL}$, and hence the highest anaemia prevalence during pregnancy $(38.3 \%)$ was in the $8^{\text {th }}$ month. The anaemia rates among the pregnant women ranged from $24-38 \%$ depending on the gestation age. However, the average haemoglobin level of most of the pregnant women remained above the level, $11.0 \mathrm{~g} / \mathrm{dL}$, below which anaemia during pregnancy is diagnosed [16]. The gestation age when the pregnant women first attended the $\mathrm{MCH}$ for antenatal care correlated with haemoglobin concentration. Specifically, early attendance was associated with better haemoglobin concentration (Table 3). 


\section{DISCUSSION}

This study assessed the antenatal characteristics of 503 pregnant women in Accra, Ghana, to elucidate the importance of antenatal care to favourable outcome of pregnancy in developing countries. The importance of early antenatal care was shown by a better infant birth-weight and haemoglobin concentration for pregnant women who received early antenatal care. It was evident that a better outcome of pregnancy could be achieved if mothers seek antenatal care by the $3^{\text {rd }}$ month of pregnancy. These better outcomes can be attributed, in part, to adherence to $\mathrm{MCH}$ protocols which include maternal counselling, complete immunization coverage, longer health monitoring and longer duration of nutrients supplementation during pregnancy [18]. In Nepal, Osrin et al. [19] observed a significant improvement in birth-weight following maternal nutrients supplementation during pregnancy. However, Thomas et al. [20] observed no significant improvement in pregnancy outcome among pregnant women who received early or late antenatal care in Bristol, UK. It appears that the benefits of antenatal care could be better achieved if it is obtained early and may be more important in marginally nourished women in developing countries.

High maternal educational level correlated positively with early antenatal care seeking. It is probable that well educated women could have better access to information, and better self-drive, initiative and socio-economic status [21, 22]. All these qualities could have culminated in the better response to antenatal care attendance observed among better educated women in this study. This observation is further evidence of the importance of women's education, especially in developing countries.

The antenatal care and MVMS could barely sustain adequate haemoglobin concentration during pregnancy. The $8^{\text {th }}$ month was the most critical with haemoglobin concentrations at the lowest. Consequently, the highest anaemia rate during pregnancy was observed in the $8^{\text {th }}$ month among the participants. Hemodilution resulting in excessive accumulation of body fluid occurs around the $8^{\text {th }}$ month of pregnancy and could have contributed to the observed decreases in haemoglobin concentration in the $8^{\text {th }}$ month $[23,24]$. Nevertheless, the positive association of the duration of antenatal care and nutrients supplementation with maternal haemoglobin concentration stress the importance of the MVMS program and of a good level of maternal compliance to the norms of antenatal care. These findings place further emphasis on the importance of antenatal care and nutrient supplementation to favourable outcome of pregnancy.

\section{CONCLUSION}

From the above results, it was concluded that early antenatal care is important to a favourable outcome of pregnancy in developing countries. Programs to improve pregnancy outcome should include promotion of maternal literacy, and early and regular antenatal care.

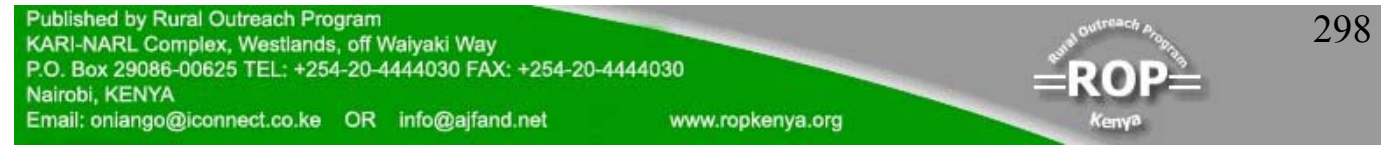




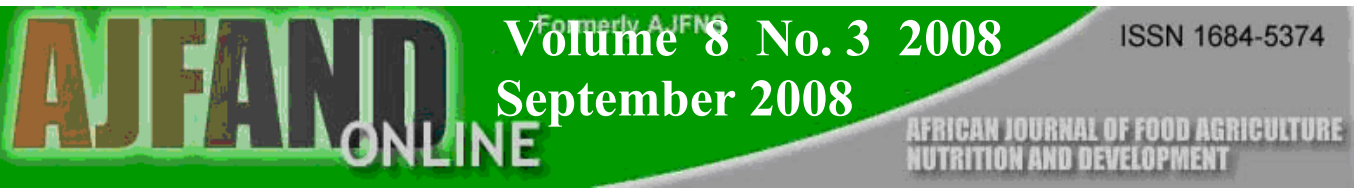

Table 1: Characteristics of pregnant women in this study $(n=503)$

\begin{tabular}{|c|c|c|}
\hline Characteristic & $\begin{array}{l}\text { No. of } \\
\text { pregnant } \\
\text { women }\end{array}$ & $\begin{array}{l}\% \text { Pregnant } \\
\text { women }\end{array}$ \\
\hline \multicolumn{3}{|l|}{ Occupation } \\
\hline Trader & 294 & 58.45 \\
\hline Vocational & 141 & 28.03 \\
\hline Office worker & 14 & 2.78 \\
\hline Professional & 33 & 6.56 \\
\hline Housewife & 21 & 4.17 \\
\hline \multicolumn{3}{|l|}{ Marital status } \\
\hline Married & 498 & 99.49 \\
\hline Single & 5 & 0.60 \\
\hline \multicolumn{3}{|l|}{ Highest educational level } \\
\hline None & 16 & 3.18 \\
\hline Primary & 105 & 20.87 \\
\hline Middle & 248 & 49.30 \\
\hline Secondary/Technical & 127 & 25.25 \\
\hline University & 7 & 1.39 \\
\hline \multicolumn{3}{|c|}{ Previous pregnancies (parity) } \\
\hline None & 144 & 28.63 \\
\hline $1-2$ & 183 & 36.38 \\
\hline $3-4$ & 140 & 27.83 \\
\hline $5-6$ & 33 & 6.56 \\
\hline $7-9$ & 2 & 0.40 \\
\hline \multicolumn{3}{|c|}{ History of spontaneous abortion } \\
\hline 0 & 358 & 71.17 \\
\hline 1 & 105 & 20.87 \\
\hline 2 & 37 & 7.36 \\
\hline 3 & 3 & 0.60 \\
\hline \multicolumn{3}{|l|}{ History of stillbirths } \\
\hline 0 & 478 & 95.03 \\
\hline 1 & 25 & 4.97 \\
\hline
\end{tabular}


Table 2: Duration of antenatal care and multivitamin and mineral supplementation in relation to infant birth weight $(n=503)$

\begin{tabular}{lll}
$\begin{array}{l}\text { Duration } \\
\text { (months) }\end{array}$ & $\begin{array}{l}\text { Number } \\
\text { of mothers }\end{array}$ & $\begin{array}{l}\text { Infant } \\
\text { birth-weight } \\
(\mathrm{kg})^{*}\end{array}$ \\
\hline$\leq 4$ & 49 & $2.88 \pm 0.55^{\mathrm{a}}$ \\
5 & 71 & $2.83 \pm 0.41^{\mathrm{a}}$ \\
6 & 241 & $3.09 \pm 0.43^{\mathrm{b}}$ \\
7 & 104 & $3.03 \pm 0.44^{\mathrm{b}}$ \\
8 & 38 & $3.13 \pm 0.48^{\mathrm{b}}$ \\
\hline
\end{tabular}

*Length of antenatal care and multivitamin and minerals supplementation correlated with infant birth-weight, $\mathrm{r}=+0.15$

${ }^{\mathrm{ab}}$ Values with different superscripts are significantly different, $\mathrm{P}<0.05$, Duncan's method. 


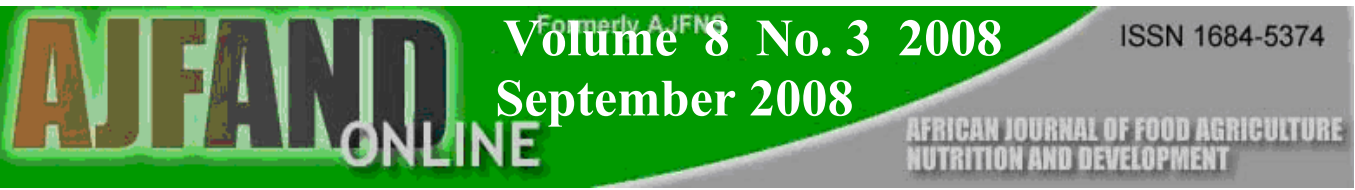

Table 3: Mean haemoglobin concentration during pregnancy in relation to gestation age of first antenatal care attendance $(n=128)$

\begin{tabular}{ccc}
\hline $\begin{array}{c}\text { Gestation age } \\
\text { (Months) }\end{array}$ & $\begin{array}{c}\text { Number } \\
\text { of pregnant } \\
\text { women }\end{array}$ & $\begin{array}{c}\text { Mean maternal } \\
\text { haemoglobin level } \\
(\mathrm{g} / \mathrm{dL})^{*}\end{array}$ \\
\hline 1 & 15 & $11.62 \pm 0.33^{\mathrm{a}}$ \\
2 & 15 & $11.78 \pm 0.59^{\mathrm{a}}$ \\
3 & 75 & $11.62 \pm 0.58^{\mathrm{a}}$ \\
4 & 12 & $10.94 \pm 0.35^{\mathrm{b}}$ \\
$\geq 5$ & 11 & $10.83 \pm 0.49^{\mathrm{b}}$ \\
\hline
\end{tabular}

*Anaemia cut-point: haemoglobin $<11.0 \mathrm{~g} / \mathrm{dL}^{16}$

${ }^{\mathrm{ab}}$ Values with different superscripts are significantly different, $\mathrm{P}<0.05$, Duncan's method. 


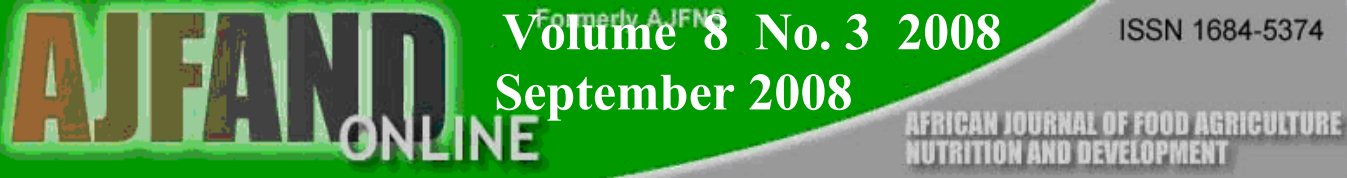

\section{REFERENCES}

1. UNICEF. Maternal Health. Retrieved in June 2006 from:

http://www.unicef.org/health/index maternalhealth.html 2006

2. USAID. Maternal and neonatal program effort index. Rating Maternal and Neonatal Health Programs in Developing Countries. University of North Carolina Population Centre, 2002: 1-8.

3. UNICEF. State of the world's children, 1991. Oxford University Press, U.K.

4. Population Action International Sexual and reproductive health in Ghana and the role of donor assistance, 2004. Retrieved in July 2005 from: http://www.populationaction.org/resources/publications/progressandpromises/dow nloads/2-PandP-Ghana.pdf 2005.

5. UNICEF. Ghana country statistics. Retrieved in June 2006 from: http://www.unicef.org/infobycountry/ghana.html. 2006.

6. UNICEF. State of the world's children, 2005. Oxford University Press, U.K.

7. Food and Nutrition Board Maternal nutrition and the course of pregnancy. Committee on maternal nutrition. National Academy of Science, N.R.C. Washington D.C., 1971.

8. WHO. Maternal and infant nutrition in developing countries, with special reference to possible intervention programs in the context of health. Food and Nutr Bull, 1984: 6(4); 43-60.

9. Hudson T Pregnancy and the use of nutritional supplements. Women's health update. Townsend letter for doctors and patients. Retrieved in July 2005 from: http://www.findarticles_com/p/articles/mi_m0ISW/is_2002_Jan/ai_81138282. 2005.

10. Brown J Nutrition and pregnancy: A guide from preconception to post-delivery. Retrieved in June 2005 from: http://my.webmd.com/content/article/4/1680 51794.htm. 2005

11. Parul C Dietary supplements use in women: Current status and future directions. Micronutrients and reproductive health issues: An international perspective. $\mathrm{Am}$ Soc Nutr Sc, 2003 1969S-1973S.

12. USAID. The enable project. Highlight on mobilizing communities for safe motherhood. January 2003:1-2. 
13. Zavaleta N, Caulfield LE, and T Garcia Changes in iron status during pregnancy in Peruvian women receiving prenatal iron and folic acid supplements with or without zinc. Am J Clin Nutr, 2000; 71: 956-61.

14. FAO/WHO. Conducting small scale nutrition surveys: A field manual. Nutrition planning, assessment and evaluation service. Food Policy and Nutrition Division. Nutrition in Agriculture, 1990;5:39-55.

15. Wooton IDP Micro Analysis in Medical Biochemistry. $4^{\text {th }}$ ed. Churchill, London, 1964.

16. Tomkins A and F Watson Controlling Iron Deficiency. ACC/SCN state of the Art Series. Nutrition Policy Discussion Paper No. 9, 1991.

17. WHO. Expert Committee on Maternal and Child Health. Public Health Aspects of Low Birth-weight. In: Maternal Nutrition and the Course of Pregnancy. Food and Nutrition Board, National Research Council. Washington D.C. 1961.

18. WHO. Reproductive health. Retrieved in July 2005 from: http://www.who.int/reproductivehealth/publications/MSM 96 8/MSM_96_8 chapter1.en.html. 2005

19. Osrin D, Vaidya A, Shrestha Y, Baniya RB, Manandhar DS, Adhikari RK, Filteau S, Tomkins A, and AM Costello Effects of antenatal multiple micronutrient supplementation on birthweight and gestational duration in Nepal: double-blind, randomised controlled trial. Lancet, 2005 Mar 12;365(9463):916-7.

20. Thomas $\mathbf{P}$, Golding $\mathbf{J}$ and $\mathbf{T J}$ Peters Delayed antenatal care: does it affect pregnancy outcome? Soc Sci Med, 1991;32(6):715-23

21. Women Employed Institute Campaign to increase women's access to education and training. The facts 2001 . Retrieved in July 2006 from: http://www.un.org/News/Press/docs/2000/20000127.wom1168.doc.html. 2006

22. United Nations Commission on the status of women. Fiftieth Session, New York, 27 Feb-March $10^{\text {th }}, 2005$. Retrieved in July 2006 from: http://www.un.org/ womenwatch/daw/csw/csw50/statements/CSW\%2050\%20-\%20Panel\%20I\% 20\%20Bernadette\%20Lahai\%20.pdf. 2006.

23. The Merck Manual of Diagnosis and Therapy Retrieved in July 2006 from: http://www.merck.com/mrkshared/mmanual/section18/chapter251/251k.jsp. 2006

24. Thomas N Physiologic changes of pregnancy. Retrieved in July 2006 from: http://www.utmem.edu/obgyn/res_pres/Physiologic\%20changes\%20of\%20pregna nc.pdf. 2006. 